\title{
O movimento das pesquisas em Modelagem Matemática em Minas Gerais - Brasil
}

\author{
The movement of researches in Mathematical Modelling in Minas Gerais - Brazil
}

\author{
Neil da Rocha Canedo Jr. ${ }^{1}$ \\ neilcanedo@gmail.com
}

\author{
Marco Aurélio Kistemann Jr. ${ }^{2}$ \\ marco.kistemann@ufjf.edu.br
}

\begin{abstract}
Resumo
Esse artigo apresenta um estudo teórico que visa compor o estado da arte da produção científica em Modelagem Matemática, no âmbito da Educação Matemática em Minas Gerais (Brasil). Nossa investigação buscou trilhar os caminhos da pesquisa em Modelagem no estado de Minas Gerais, tendo o contexto nacional das pesquisas em Modelagem Matemática como pano de fundo, por meio de um levantamento qualitativo e quantitativo. Nossa pesquisa revelou um estado de incipiência relativo ao momento atual da pesquisa mineira em Modelagem Matemática. Esse estado da arte reflete algumas tendências e perspectivas presentes no cenário nacional. Por outro lado, percebemos certas especificidades que mostram que a Modelagem mineira não apenas reflete as tendências nacionais, mas que também assume identidade própria.
\end{abstract}

Palavras-chave: Estado da arte. Modelagem matemática. Etnomodelagem. Revisão bibliográfica.

\begin{abstract}
This article presents a theoretical study that aims to make the state of the art scientific production in mathematical modelling in the context of mathematics education in Minas Gerais (Brazil). Our research sought to tread the paths of Modeling research in the Minas Gerais State, having the national context of research in mathematical modelling as a backdrop, by means of a qualitative and quantitative survey. Our research revealed a state of low relative to the current time of mineira research in mathematical modeling. This state of the art reflects some trends and present perspectives on the national scene. On the other hand, we perceive certain

\footnotetext{
${ }^{1}$ Mestrando do Mestrado Profissional em Educação Matemática da Universidade Federal de Juiz de Fora UFJF. Docente da Rede Pública Estadual e Municipal de Juiz de Fora, MG.

${ }^{2}$ Doutor em Educação Matemática pela Universidade Estadual Paulista Júlio de Mesquita Filho, Unesp-Rio Claro, SP. Professor Adjunto do Departamento de Matemática - UFJF e Docente do Mestrado Profissional em Educação Matemática - UFJF.
} 
specifics that show that mineira modeling does not only reflect national trends, but that also assumes its own identity.

Keywords: State of the art. Mathematical modeling. Etnomodeling. Literature review.

\section{Introdução}

Esse artigo apresenta um ensaio teórico baseado em um estudo a respeito da produção científica em Modelagem no âmbito da Educação Matemática no estado de Minas Gerais (Brasil). Trata-se de uma pesquisa bibliográfica que teve como lócus investigativo os trabalhos acadêmicos (teses e dissertações) e as publicações de autoria de professores/pesquisadores e/ou estudantes de universidades mineiras.

Considerando os objetivos delineados, nossa pesquisa apresenta alguns aspectos presentes no paradigma investigativo denominado Estado da Arte. Por se tratar de uma tendência investigativa que se preocupa em desenvolver estudos voltados para a sistematização da pesquisa já desenvolvida, por meio de estudos transversais que permitam descortinar perspectivas e tendências predominantes, assim como referências teóricas utilizadas (CACHAPUZ, 2003).

Pesquisas realizadas nessa linha de inquérito tratam de sistematizar o conhecimento acumulado, de forma atualizada, ou seja, de apresentar um retrato atualizado da área. Nesse sentido, são pesquisas

Definidas como de caráter bibliográfico, que trazem o desafio de mapear e de discutir uma certa produção acadêmica em diferentes campos do conhecimento, tentando responder que aspectos e dimensões vêm sendo destacados e privilegiados em diferentes épocas e lugares, de que formas e em que condições têm sido produzidas certas dissertações de mestrado, teses de doutorado, publicações em periódicos e comunicações em anais de congressos e de seminários. (FERREIRA, p. 257, 2002).

Nossa investigação buscou tanto trilhar os caminhos da pesquisa em Modelagem no estado de Minas Gerais, como descortinar as sendas deixadas em aberto, esperando por serem exploradas. Assim, esse trabalho se dirige principalmente àqueles que pretendem enveredar por essas paisagens, fazendo da Modelagem sua região de inquérito.

Apresentamos primeiramente, um levantamento estritamente quantitativo, no qual contabilizamos as dissertações e teses produzidas nas universidades mineiras, até então, que têm a Modelagem como lócus investigativo. Enumeramos também os artigos publicados, em 
periódicos ou na forma de capítulos de livro, por professores/pesquisadores que atuam nas universidades mineiras que adotam a Modelagem como linha de pesquisa. Por fim, fizemos uma contagem dos trabalhos presentes nos anais das últimas edições dos principais eventos regionais mineiros que têm a Educação Matemática como tema.

É importante ressaltar que esse levantamento considerou os trabalhos publicados e disponíveis nos bancos de teses e dissertações das universidades mineiras, artigos publicados em periódicos por professores/pesquisadores e/ou alunos daquelas instituições, além dos anais dos últimos encontros regionais realizados naquele estado. Esse mapeamento revelou que as pesquisas em Educação Matemática nas universidades mineiras tiveram início em 1998. Como nossas buscas foram realizadas até o dia 30/03/2014, essas duas datas configuram um recorte temporal em nossa investigação.

Foi a partir desse levantamento quantitativo que definimos o contexto da nossa análise bibliográfica. Nessa revisão de literatura consideramos, primeiramente, as teses e dissertações e, posteriormente, os artigos publicados em periódicos ou livros. Optamos por não considerar os trabalhos publicados nos anais dos eventos regionais nessa análise bibliográfica pelo fato de, na maioria deles, não ser possível revelar perspectivas e tendências a respeito da pesquisa que descrevem. Ressaltamos ainda que um bom número desses textos consiste de relatos de experiência ou comunicações científicas, a respeito de pesquisas que se encontram em estágio inicial, algumas delas se referindo a trabalhos de conclusão de curso voltados para revisões de literatura.

A partir desse estudo, procuramos também apresentar as tendências em Educação e em Educação Matemática presentes nessa produção, considerando os aportes teóricos utilizados, as metodologias empregadas e os objetivos das pesquisas realizadas, o que nos permitiu descortinar sendas de pesquisas a serem exploradas. Além disso, a leitura de trabalhos como Malheiros (2012) e Tambarussi e Klüber (2014) possibilitou-nos algumas comparações entre o contexto mineiro e o contexto nacional, no que se refere às pesquisas em Modelagem.

Enquadramos nossa pesquisa em uma pesquisa qualitativa de acordo com as características descritas por Bogdan e Biklen (1994), em que o pesquisador se torna o principal instrumento, na qual os dados coletados ou produzidos são predominantemente descritivos e a preocupação com o processo é muito maior do que com o produto, de modo que a análise de dados tende a seguir um processo indutivo. 
A relevância de estudos, com abordagem qualitativa, como o que apresentamos numa escala micro, pode ser justificada em pesquisas em escala macro, como a realizada por Silva e Klüber (2012), por exemplo, que em um artigo questionam: 'Em que níveis estão focados as pesquisas brasileiras sobre a Modelagem Matemática na Educação Matemática e o que isso revela?". Nessa investigação, os autores destacam que ainda são poucas as pesquisas em Modelagem Matemática direcionadas às séries iniciais.

Além disso, identificar o que tem sido pesquisado em Modelagem pode, de acordo com Romanowski e Ens (2006, p.9), significa uma contribuição importante na constituição do campo teórico da área de conhecimento, no caso, a Modelagem Matemática.

A escassez de trabalhos voltados para o mapeamento das pesquisas em Modelagem, voltados para contextos regionais, vão ao encontro do que percebemos em nossa revisão de literatura, na qual não encontramos trabalhos focados no estudo da produção em Modelagem em contextos regionais.

No sentido de preencher parte dessa lacuna que apresentamos uma análise da produção científica em Modelagem no estado de Minas Gerais. Esclarecemos que foi feito um recorte temporal para o levantamento dessa produção, com pesquisas analisadas de 1998 até 2014.

\section{A prática de revisões de literatura e revisões bibliográficas}

É prática comum entre aqueles que desenvolvem trabalhos acadêmicos tendo a Modelagem como temática, fazer uma revisão da literatura das pesquisas realizadas nessa área com o intuito de revelar questões em aberto. Há também aqueles estudos especificamente voltados para a análise de tendências e perspectivas dentro dessa região de inquérito. Dente os quais podemos destacar Barbosa (2007), Araújo, et al (2009), Malheiros (2012) e Tambarussi e Klüber (2014).

Barbosa (2007), por exemplo, faz uma revisão de literatura nos textos submetidos para publicação no livro (BARBOSA; CALDEIRA; ARAÚJO, 2007), essa análise foi construída, a partir de cinco categorias: objetivo, coerência, referencial teórico, metodologia e credibilidade da pesquisa. Já Araújo, et al (2009) apresenta um panorama das investigações sobre Modelagem publicadas nos anais dos principais eventos nacionais da área entre $2006 \mathrm{e}$ 2007, tomando como escopo analítico os objetivos dessas pesquisas. 
Em trabalhos mais recentes, Malheiros (2012) apresenta um ensaio teórico construído a partir de uma revisão de literatura sobre as pesquisas em Modelagem em todo o território brasileiro. A autora busca, primeiramente, evidenciar a presença de outras tendências da Educação e da Educação Matemática que são abordadas nas pesquisas em Modelagem. Dentre essas tendências, ela destaca a pedagogia de projetos, o uso das Tecnologias da Informação e Comunicação (TICs), a Etnomatemática e a resolução de problemas. A autora também faz uma análise dos referencias teóricos presentes nas pesquisas em Modelagem enfatizando a forte presença da Educação Matemática Crítica, da noção de interesse de John Dewey, e da interdisciplinaridade, além de alguns trabalhos que evocam questões filosóficas.

Tambarussi e Klüber (2014) utilizaram-se do Banco de Teses da Capes para fazerem um levantamento das dissertações e teses que apresentavam os temos Modelagem Matemática e Educação Matemática em seus resumos. Dos setenta e seis trabalhos levantados, dos quais sessenta e seis dissertações de mestrado e dez teses de doutorado, produzidas no período de 1989 a 2011, os autores fizeram um mapeamento pelo qual identificaram seis categorias constituídas a partir dos próprios dados: aplicação da Modelagem em Diferentes perspectivas, aprendizagens no contexto da Modelagem, mapeamento da utilização da Modelagem, modelagem e conteúdo matemático, Modelagem e aspectos teóricos, filosóficos e epistemológicos, e a formação de professores e a Modelagem.

A categoria referente aos trabalhos voltados para o mapeamento da utilização da Modelagem é a que apresenta o menor número de trabalhos, com apenas três, dos setenta e seis trabalhos. Nesta categoria se encontram as pesquisas voltadas para o que os autores denominam metaestudos sobre a Modelagem no âmbito da Educação Matemática, o que aproxima essa classe de pesquisas dos objetivos a que nos propomos nesse trabalho,

[...] haja vista que elas olham para aquilo que tem sido pesquisado na área, de tal modo que buscam explicitar as principais temáticas abordadas, os temas que podem que podem ser aprofundados e, aqueles que ainda não foram contemplados. Esse tipo de investigação pode, por um lado, evitar repetições nos temas investigados. E, por outro lado, solicitar aprofundamento em pesquisas que parecem repetitivas, mas que podem indicar outros caminhos (TAMBARUSSI; KLÜBER, 2014, p. 219).

Além disso, dos três trabalhos identificados pelos autores dentro dessas características, apenas um apresenta um estudo de caráter regionalista que se dedicou a mapear as ações educacionais que utilizaram da Modelagem no ensino catarinense. 
A escassez de trabalhos voltados para o mapeamento das pesquisas em Modelagem, voltados para contextos regionais, vão ao encontro do que percebemos em nossa revisão de literatura na qual não encontramos trabalhos focados no estudo da produção em Modelagem em contextos regionais. É no sentido de preencher parte dessa lacuna, que apresentamos uma análise da produção científica em Modelagem no estado de Minas Gerais.

\section{Levantamento quantitativo e definição do contexto}

Objetivando realizar um levantamento quantitativo das pesquisas mineiras em Modelagem, iniciamos uma busca nos bancos de teses e dissertações das várias universidades mineiras e no Currículo do Sistema Lattes dos professores/pesquisadores que atuam nos departamentos de Matemática ou Educação dessas instituições. Com isso, destacamos aquelas instituições de ensino superior em que há programas de pós-graduação em Educação Matemática em funcionamento, ou mesmo indícios de pesquisas relativas a essa região de inquérito.

Após a identificação das dissertações, teses e artigos, passamos ao processo de leitura e análise do material coletado, a fim de identificar as temáticas de pesquisa, metodologias e procedimentos e referenciais teóricos presentes nas pesquisas em Modelagem em solo mineiro.

Essa busca inicial revelou que em duas universidades mineiras há programas de pósgraduação específicos na área de Educação Matemática. Ambos lotados em seus departamentos de matemática: a Universidade Federal de Ouro Preto (UFOP) ${ }^{3}$ e a Universidade Federal de Juiz de Fora (UFJF) ${ }^{4}$, com seus mestrados em Educação Matemática na modalidade profissional.

A Universidade Federal de Minas Gerais (UFMG), a Universidade Federal de Uberlândia (UFU) ${ }^{5}$, assim como a própria Universidade Federal de Juiz de Fora (UFJF), desenvolvem em seus respectivos departamentos de Educação, pesquisas no campo da Educação Matemática.

Além das universidades supracitadas, encontramos na Universidade Federal dos Vales do Jequitinhonha e Mucuri (UFVJM) ${ }^{6}$ uma produção acadêmica incipiente em Educação Matemática. Produção esta que se faz revelar na presença de professores especialistas em

\footnotetext{
${ }^{3}$ Disponível em: <http://www.ppgedmat.ufop.br $>$ - último acesso em 30/03/2014.

${ }^{4}$ Disponível em: < http://www.ufjf.br/mestradoedumat $>$ - último acesso em 30/03/2014.

${ }^{5}$ Disponível em: http://www.ppged.faced.ufu.br/node/84> - último acesso em 30/03/2014.

${ }^{6}$ Disponível em: <http://www.ufvjm.edu.br> - último acesso em 30/03/2014.
} 
Educação Matemática em seus departamentos de Matemática, atuando tanto na graduação, como na especialização no ensino da matemática oferecido por esse departamento, com destaque para o evento "Encontro de Educação Matemática do Nordeste Mineiro (ENEMANM)",

Também, pesquisamos os anais dos eventos mineiros, de caráter regional, que têm a Educação Matemática como temática. São eles: os Encontros Mineiros de Educação Matemática (EMEMs), os encontros de Educação Matemática de Ouro Preto (EEMOPs), assim como os Colóquios de Educação Matemática da Universidade Federal de Juiz de Fora (UFJF).

Sobre a importância desses eventos, vale ressaltar que a realização do I EMEM, em Ouro Preto (MG) em 1998, foi o encontro inaugural dos eventos científicos e o início oficial das pesquisas em Educação Matemática em Minas Gerais. Foi no âmbito desse evento que se constituiu a diretoria regional mineira da Sociedade Brasileira de Educação Matemática (SBEM - MG), que passou a organizar bianualmente os EMEMs, tendo sido sediado por algumas das universidades mineiras.

O I EMOP veio a acontecer em 1999 como um desdobramento do I EMEM e vem sendo regularmente organizado e sediado pela UFOP, contando também com a colaboração da SBEM-MG ${ }^{8}$.

O Colóquio de Educação Matemática promovido pela UFJF possui uma história mais recente. O primeiro evento foi realizado em 2006 pela referida instituição e, desde então, vem sendo realizado com certa regularidade pela referida universidade. Esse evento também conta com a parceria da SBEM - MG e já é uma tradição da Educação Matemática Mineira ${ }^{9}$.

Com história ainda mais recente, temos o já referido Encontro de Educação Matemática do Nordeste Mineiro (ENEMANM), anualmente sediado e organizado pela UFVJM.

Tendo em vista esse contexto inicial, constituído por bancos de teses e dissertações, currículo do sistema Lattes dos professores pesquisadores das Universidades em que a Educação Matemática se faz presente (UFOP, UFJF, UFMG, UFU, UFVJM), além dos anais dos EMEMs, EEMOPs, Colóquios da UFJF, e ENEMANMs, realizamos um levantamento em termos estritamente numéricos da produção acadêmica mineira em Modelagem.

\footnotetext{
${ }^{7}$ Disponível em: <http://www.ufvjm.edu.br/site/enemanm $>$ - último acesso em 30/03/2014.

${ }^{8}$ Disponível em: <http://www.eemop5.ufop.br> - último acesso em 30/03/2014.

${ }^{9}$ Disponível em: < http://www.ufjf.br/nideem/coloquio-de-educacao-matematica $>$ - último acesso em $30 / 03 / 2014$
} 
Esse levantamento se deu por meio da contagem e da leitura dos resumos das dissertações e teses presentes nos bancos das referidas universidades, dos artigos publicados por professores/pesquisadores que nelas atuam e dos resumos dos trabalhos publicados nos anais dos mencionados eventos nas modalidades: comunicação científica ou relato de experiência. Além disso, contabilizamos, via currículo do sistema Lattes, os trabalhos de conclusão de curso de graduação, especialização e iniciação científica defendidos nas instituições mencionadas, já que esses não estão disponíveis nos bancos de teses e dissertações.

Na Universidade Federal de Ouro Preto (UFOP) temos um total de nove trabalhos de conclusão de curso (graduação, especialização ou iniciação científica). Desses trabalhos, quatro orientados por Dale Bean, dois por Frederico da Silva Reis, dois por Roseli Corrêa e um por Milton Rosa. No programa de Mestrado Profissional dessa universidade, temos cinco $^{10}$ dissertações de mestrado defendidas, quatro orientadas por Dale Bean e uma por Frederico da Silva Reis. A UFOP não conta ainda com programa de doutorado em que a Educação Matemática figura como linha de pesquisa. Nessa universidade, encontramos o Grupo de Estudos e Pesquisa em Modelagem Matemática no Âmbito Educacional, com registro no Conselho Nacional de Pesquisa $(\mathrm{CNPq})$ e liderado por Dale Bean.

Na Universidade Federal de Minas Gerais (UFMG) há defendidos quatro trabalhos de conclusão de cursos (graduação, especialização ou iniciação científica), duas dissertações de mestrado e uma tese de doutoramento. Todos esses trabalhos foram orientados por Jussara de Loiola Araújo. Essa mesma pesquisadora lidera o Grupo de Estudos e Pesquisa em Educação Matemática, Modelagem e Tecnologias, que funciona no âmbito dessa universidade com registro no Conselho Nacional de Pesquisa (CNPq).

$\mathrm{Na}$ Universidade Federal de Juiz de Fora (UFJF), temos até o momento um trabalho defendido intitulado "Estudando conteúdos matemáticos com direcionamentos de modelagem matemática: o caso da função afim", orientado por Orestes Piermatei Filho, além de outra pesquisa em fase final e orientada por Marco Aurélio Kistemann Jr, sobre o tema Modelagem. Assim como na UFOP, não há ainda na UFJF um programa de doutorado em que a Educação Matemática figure como linha de pesquisa, o que justifica a ausência de teses nessa linha.

\footnotetext{
${ }^{10}$ Duas dessas dissertações são referidas no currículo do sistema lattes do orientador, o Prof. Dr. Dale Bean, mas não estavam disponíveis no banco de dissertações e teses da instituição em questão até a data do dia 30/03/2014, ficando, por esse motivo, restritas ao nosso levantamento quantitativo.
} 
No quadro 1, apresentamos a totalização das teses, dissertações e dos trabalhos de conclusão de curso de graduação (Trabalhos de Conclusão de Curso-TCCs) produzidos, até então ${ }^{11}$, nas universidades do estado de Minas Gerais.

Quadro 1: Produção acadêmica sobre Modelagem em Minas
\begin{tabular}{|l|c|c|c|}
\hline INSTITUIÇÃO & TCCs & DISSERTAÇÕES & TESES \\
\hline UFOP & 9 & 5 & - \\
\hline UFMG & 4 & 2 & 1 \\
\hline UFJF & - & 1 & - \\
\hline TOTAL & 13 & 8 & 1 \\
\hline
\end{tabular}

Fonte: Currículo do Sistema Lattes dos professores bancos de teses e dissertações das Universidades.

No caso dos artigos publicados em periódicos ou em forma de capítulo de livro. A dupla de pesquisadores Milton Rosa e Daniel Clark Orey, pesquisadores da UFOP, conta com um total de dezessete trabalhos publicados, além de dois artigos publicados sob a autoria única do primeiro desses pesquisadores e uma publicação de autoria apenas do segundo. Ainda no âmbito do corpo de professores da UFOP, há dois artigos publicados por Dale Bean. Encerrando nosso levantamento quantitativo dos artigos produzidos por pesquisadores das universidades mineiras, temos onze artigos publicados pela pesquisadora Jussara de Loiola Araújo, que atua como pesquisadora no departamento de Matemática da UFMG.

No que diz respeito aos anais dos eventos regionais que tem a Educação Matemática como temática, nosso levantamento quantitativo considerou a última edição de cada um deles. Ficamos, assim, com o VI EMEM, realizado em 2012 na UFJF, com o V EEMOP, que aconteceu em 2013, na UFOP e com o III Colóquio de Educação Matemática da UFJF, realizado em 2011 na referida instituição. No caso dos Encontros de Educação Matemática do Nordeste Mineiro, não identificamos nenhum trabalho com a temática Modelagem. Nosso levantamento quantitativo considerou os trabalhos apresentados nas modalidades: comunicação científica e relato de experiência. Os resultados estão apresentados no quadro 2.

\footnotetext{
${ }^{11}$ Dados referentes ao dia 30/03/2014.
} 
Quadro 2: A presença dos trabalhos sobre Modelagem nos eventos regionais em Minas.

\begin{tabular}{|l|c|c|}
\hline Eventos & Relatos & Comunicações \\
\hline VI ENEM & 1 & 2 \\
\hline V EEMOP & 3 & 1 \\
\hline III Colóquio & 2 & 4 \\
\hline Total & 6 & 7 \\
\hline
\end{tabular}

Fonte: Anais dos eventos.

Esse levantamento estritamente quantitativo delimita o contexto de inquérito do estudo bibliográfico que realizamos sobre o Movimento das pesquisas em Modelagem em Minas Gerais. Nosso lócus foram as dissertações e teses defendidas e disponíveis nos bancos de teses e dissertações dos sites das instituições em que foram submetidas, além dos artigos publicados em periódicos por pesquisadores que atuam nas universidades de Minas e que têm a Modelagem como região de inquérito. Nessas análises, lançamos mão de categorias analíticas baseadas naquilo que consideramos os três pontos chaves nas pesquisas qualitativas: objetivos, referencial teórico e metodologia.

Como mencionamos anteriormente, optamos por não considerar os trabalhos apresentados nos eventos regionais por se referirem, em grande parte, a relatos de experiências sem qualquer referência teórico-metodológica, ou comunicações científicas referentes a pesquisas em estágio inicial nas quais ainda não é possível clarear os objetivos, a metodologia, os referenciais teóricos e os resultados obtidos.

\section{A "Modelagem Mineira": um panorama das teses e dissertações}

Neste item apresentamos os contextos, temas, opções teórico-metodológicas de pesquisas realizadas com o tema Modelagem realizadas em solo mineiro. Nossa revisão bibliográfica se dirige primeiramente às teses e dissertações defendidas até março de 2014 no âmbito das universidades mineiras, e que constam dos bancos de teses e dissertações das referidas universidades. 
Nesse primeiro contexto temos: Freitas (2013), única tese de doutorado que encontramos e que foi defendida na UFMG; as dissertações Mellilo (2011), Abreu, G. (2011) e Bueno (2011), as três defendidas na UFOP; Campos (2013), Silva (2012), ambas apresentadas e aprovadas para defesa à UFMG; e Abreu, L. (2011), a única dissertação defendida na UFJF até o momento.

Em Mellilo (2011), o foco central da pesquisa são as possibilidades da Modelagem frente ao desenvolvimento de uma educação progressiva. Nessa concepção de educação, elaborada e defendida por Dewey (1959) valoriza-se a assunção por parte do aluno de uma postura ativa e criadora de conhecimentos, em detrimento àquelas práticas letivas tradicionais voltadas para um aluno receptivo e dependente do professor e dos livros.

Essa concepção de Educação está em consonância com as perspectivas de Modelagem do autor, concebida como uma atividade que se constitui sustentada em uma premissa, uma ideia maior que nem sempre parte do modelador (aluno), no âmbito da qual ele vai assumindo, avaliando, validando e/ou refutando pressupostos, que são conceituações do modelador relativas a aspectos específicos da situação que pretende modelar.

No decurso da pesquisa são feitas associações entre a Modelagem e alguns aportes teóricos da Educação Estatística, como a noção de probabilidade subjetiva, a qual considera o grau de certeza que o observador atribui a determinado evento, a partir de suas observações pessoais (GNEDENKO 2008).

Quanto aos procedimentos metodológicos, o autor enfatiza a ressonância entre esses procedimentos, seus objetivos investigativos e suas concepções de Educação e de Modelagem. Trata-se de uma pesquisa de cunho qualitativo, desenvolvida no contexto de uma turma de licenciatura em Matemática.

Abreu, G. (2011) apresenta uma pesquisa voltada para as relações entre o desenvolvimento de projetos de Modelagem, por parte de professores egressos de uma disciplina sobre Modelagem do referido programa e a formação continuada desses professores.

As concepções de Modelagem assumidas pelo autor se amparam, em certa medida, em Burak (2006) que privilegia a capacidade dos alunos de acionar seus conhecimentos matemáticos adquiridos e, a partir destes, construir novos conhecimentos, mediante as situações-problemas que as práticas de Modelagem suscitam. Nessa perspectiva de Modelagem, a noção de modelo 
matemático, ganha um significado bastante amplo, podendo assumir a forma de gráficos, tabelas, listas de compra ou até mesmo inferências explicitadas oralmente.

O autor dessa dissertação também busca sustentar suas concepções de Modelagem em pressupostos da Educação Matemática Crítica. Nessa perspectiva teórica, um ambiente de Modelagem consiste em um cenário para investigação em que os alunos levantam questões e procuram soluções no âmbito de uma temática com referências na realidade. Dessa forma, os objetivos didáticos se voltam para o desenvolvimento de uma competência crítica e uma aprendizagem preocupada com os papeis sociais da Matemática e dos modelos matemáticos na sociedade altamente tecnológica que vivenciamos (SKOVSMOSE, 2001).

Sobre os procedimentos metodológicos, o autor lança mão de respostas dadas a questionários abertos e entrevistas (BOGDAN; BIKLEN, 1994) com os participantes de grupos de trabalho que se constituíram na disciplina sobre Modelagem Matemática, no programa de mestrado da UFOP, no ano de 2010. Por meio de uma análise qualitativa, o autor procura explicitar as perspectivas reveladas pelos participantes a partir da análise de suas respostas aos questionários, entrevistas e através de suas observações.

Ao explicitar suas considerações finais, o autor reafirma suas concepções de Modelagem, baseadas nas preocupações da Educação Matemática Crítica ao considerar que uma característica importante da Modelagem é favorecer a formação de uma postura de criticidade e reflexividade nos alunos. Enfatizando a importância da presença da Modelagem na formação continuada dos professores de Matemática, propiciando situações em que o professor experiência a Modelagem como aluno.

Bueno (2011) faz um levantamento comparativo das perspectivas de Modelagem no cenário brasileiro. Após uma revisão geral da literatura sobre essa temática, a autora focaliza as concepções de Modelagem de quatro educadores matemáticos com relevante produção acadêmica na área: Maria Salett Biembengut, Dionísio Burak, Jonei Cerqueira Barbosa e Dale Bean.

A autora utiliza-se ainda de dois procedimentos metodológicos: a revisão bibliográfica das publicações dos referidos autores e a análise de um questionário por eles respondido. A partir da análise desses materiais, a autora apresenta alguns consensos nas diferentes perspectivas dos quatro colaboradores, visto que, todos acreditam que a Modelagem traz contribuições positivas para a sala de aula. Por outro lado, foram identificadas algumas singularidades 
relevantes, que se evidenciam nas maneiras de condução do processo de modelagem, nas significações do termo Modelagem, e, principalmente, nos objetivos educacionais dessa prática letiva. Enquanto que para Biembengut, modelagem é um método de ensino, para Burak, é uma metodologia de ensino. Para Barbosa, um ambiente de ensino e aprendizagem, enquanto que para Bean, uma atividade humana com noções de premissas e pressupostos (BUENO, 2011, p. 96).

Em Freitas (2013), a única tese de doutorado em Minas que tem a Modelagem como tema, os objetivos investigativos se voltam para o processo de matematização em um projeto de Modelagem orientado na perspectiva da Educação Matemática Crítica, que foi desenvolvido por um grupo de alunos de uma turma de $3^{\circ}$ ano do ensino médio técnico.

O autor faz uma análise qualitativa do processo de matematização com base nas ideias de educadores matemáticos como Ubiratan D’Ambrósio e Ole Skovsmose, e educadores como Paulo Freire e Henry Giroux. Como sugerem os aportes teóricos, as concepções de Modelagem do autor transparecem alinhadas aos de uma Educação Matemática voltada para uma formação humanista, crítica e libertadora.

A pesquisa permite ao autor concluir que nas práticas de Modelagem entrecruzam-se pressupostos trazidos das esferas educacionais tradicionais, muitas vezes embebidos da ideologia da certeza matemática (BORBA; SKOVSMOSE, 1997). Por outro lado, as práticas de Modelagem, quando orientadas segundo as preocupações da Educação Matemática Crítica e na presença das novas tecnologias computacionais, tendem a colaborar no sentido de desafiar e enfraquecer essa ideologia.

Campos (2013) apresenta uma pesquisa desenvolvida no contexto de dois grupos de cinco alunos da disciplina Matemática, em um curso de graduação em Gestão Pública, quando da realização de projetos de Modelagem. O foco investigativo foi o envolvimento dos alunos dos grupos nos respectivos projetos mediante a hipótese de que o background e o foreground dos alunos interferem na maneira como eles se envolvem nesse ambiente de aprendizagem.

As noções de background e foreground são aportes teóricos presentes na Educação Matemática Crítica. O background se refere às origens culturais de uma pessoa e ao contexto sócio-histórico, em que se encontra imersa, enquanto que o foreground tem a ver com as expectativas futuras dessa pessoa, consideradas a partir de seu contexto histórico e sociocultural (SKOVSMOSE, et. al., 2009). 
Em coerência com seus objetivos investigativos, Campos (2013) desenvolve uma pesquisa de cunho qualitativo. Os procedimentos metodológicos foram observações não estruturadas e participantes e entrevistas semiestruturadas, seguidas da organização os dados em categorias compostas por episódios. Os resultados aí obtidos apontam que os backgrounds e foregrounds dos indivíduos sugerem diferentes tipos de envolvimentos em ambientes de modelagem. Dessa forma, a compreensão desses envolvimentos demanda analisar de que forma os backgrounds e foregrounds se manifestam nas relações coletivas no ambiente de Modelagem.

Silva (2012) traz como foco investigativo a compreensão das possibilidades e limites vivenciados por uma professora de matemática em sua primeira experiência com modelagem na Educação Matemática, em uma turma de primeiro ano de uma escola de nível médio profissionalizante. Como consequência dos objetivos investigativos, a autora busca aportes teóricos no contexto da formação de professores, adotando a concepção de uma formação contínua, que parte da ação docente, fazendo dos problemas do cotidiano docente o ponto de partida e de chegada, o que permite o avanço de reflexões e estudos em direção a possíveis soluções próximas da realidade da escola (FIORENTINI; NACARATO, 2005).

Ao descrever a parte empírica do trabalho, a autora esclarece suas perspectivas de Modelagem em consonância com as de Barbosa (2001, p. 31), para quem a "Modelagem Matemática é um ambiente de aprendizagem em que os alunos são convidados a indagar e/ou investigar, por meio da matemática, situações oriundas de outras áreas da realidade”.

Esta investigação de cunho qualitativo, realizada por meio da análise dos dados coletados através de observação participante, entrevistas semiestruturadas e notas no caderno de campo, mostrou que a relação com o tempo e a imprevisibilidade, comuns às práticas com modelagem, gerou momentos de tensões. Entretanto, ressalta a autora da pesquisa que essas tensões não se configuraram em limites, visto que a autora fez uma avaliação positiva da experiência, revelando a intenção de realizar futuras experiências com Modelagem.

Em Abreu, L. (2011), o foco investigativo foi trabalhar o conceito de função afim por meio da Modelagem como abordagem pedagógica. A autora assume a Modelagem como uma possibilidade para quebrar o paradigma tradicional vigente na Educação Matemática, baseado na linearidade e na transmissão de conteúdos. O cenário da pesquisa é um grupo de alunos do primeiro ano de ensino médio em uma pizzaria, um contexto não escolar, em que alunos buscam relacionar grandezas como diâmetro, área e preços de pizzas. 
A prática de Modelagem investigada foi dividida nas etapas sugeridas por Burak (2004). Embora noções relativas aos pressupostos da Educação Matemática Crítica sejam apresentadas ao longo do trabalho, esses pressupostos teóricos não se fazem presente nas práticas de Modelagem e são referidos timidamente nas considerações finais. A pesquisa se desenvolve com base no paradigma investigativo do estudo caso (BOGDAN; BIKLEN, 1994). A autora conclui que a Modelagem oferece possibilidades de mudanças no paradigma vigente na tradição da Educação Matemática escolar, principalmente quanto ao ensino do conceito de função, e que os alunos clamam por essas mudanças.

\section{"Modelagem Mineira": o conteúdo das publicações}

Neste item apresentamos as publicações e as opções teórico-metodológicas feitas pelos pesquisadores em suas investigações com o tema Modelagem em solo mineiro.

A produção mineira em Modelagem, além das teses e dissertações mencionadas, se reflete, também, em artigos publicados por docentes das universidades mineiras.

Em Araújo (2009), a educadora matemática Jussara Araújo busca esclarecer suas concepções de Modelagem alinhadas àquelas da perspectiva sóciocrítica da Modelagem, assumindo aportes teóricos da Educação Matemática Crítica. Araújo et al (2011) analisa uma tarefa de Modelagem, baseada na perspectiva sóciocrítica, desenvolvida por um grupo de alunos do curso de Geografia de uma universidade pública mineira. Já em Araújo (2012) a autora investiga as atitudes críticas dos alunos em uma prática de Modelagem voltada para os aspectos socioeconômicos do projeto de construção da Linha Verde em Belo, também desenvolvida por um grupo de alunos do curso de Geografia.

Nesse último trabalho, a autora concluiu que a postura crítica dos alunos nem sempre coincide com a noção de crítica defendida pela Educação Matemática Crítica, principalmente no que diz respeito ao apoio que buscam em certezas matemáticas, de forma inquestionável, para realizar análises e chegarem a conclusões, corroborando uma ideologia da certeza da matemática (BORBA; SKOVSMOSE, 1997).

Vale ressaltar que as perspectivas de Modelagem da educadora Jussara Araújo se refletem nos referencias teóricos da tese (FREITAS, 2013) e das dissertações (CAMPOS, 2013; SILVA, 2012) por ela orientadas, no âmbito do programa de pós-graduação em Educação da UFMG. 
A presença desses aportes teóricos reflete, no âmbito nacional das pesquisas em Modelagem, os resultados obtidos por Malheiros (2012) a respeito da notória presença da Educação Matemática Crítica na quase totalidade dos trabalhos investigado pela autora. Essa presença também reflete, embora de forma menos direta, as conclusões de Tambarussi e Klüber (2014) que identificaram, dentre os trabalhos voltados para as aprendizagens no contexto da Modelagem, pesquisas voltadas para o desenvolvimento do pensamento reflexivo e o crescimento político dos alunos, com os quais a Educação Matemática Crítica se preocupa.

Em Mellilo e Bean (2011), os autores buscam esclarecer suas perspectivas de Modelagem alinhadas aos pressupostos da Educação Progressiva de John Dewey. Para esses autores, a Modelagem consiste de uma atividade que envolve conceituação e criatividade, a qual remete aos objetivos, conhecimentos e valores do modelador. Conceituação que se realiza, a partir da adoção de uma premissa, uma ideia geral, e a assunção de pressupostos, conceituações específicas sobre a situação a ser modelada. Em Mellilo (2011), dissertação orientada por Dale Bean, tais concepções de Modelagem se materializam em uma atividade de Modelagem desenvolvida por alunos de um curso de Licenciatura em Matemática.

Malheiros (2012) também identificou a presença das concepções educacionais de Dewey em seu trabalho voltados para as pesquisas no âmbito nacional, porém, os trabalhos identificados pela autora se voltam para a noção de interesse, a qual não se faz presente nem em Mellilo e Bean (2011), nem tampouco em Mellilo (2011). Tais similaridades e particularidades, por um lado relacionam os referidos trabalhos com aqueles em que as concepções educacionais de Dewey se fazem presente e, por outro, sinaliza para uma possível singularidade da Modelagem mineira.

Outra importante contribuição para a pesquisa mineira em Modelagem são os artigos publicados, em forma de ensaio teórico, pelos professores/pesquisadores Daniel Orey e Milton Rosa (ROSA; OREY, 2003; 2005; 2012; 2013), ambos do corpo docente do programa de Mestrado Profissional em Educação Matemática (UFOP).

Os autores buscam trazer para a pesquisa em Modelagem, enquanto prática curricular, aportes teóricos da Etnomatemática. Propõem, assim, a noção de Etnomodelagem, que "pode ser considerada como o estudo das práticas matemáticas desenvolvidas pelos membros dos grupos culturais distintos por meio da modelagem" (ROSA; OREY, 2012, P. 868). 
É importante destacarmos que as relações entre Modelagem e Etnomatemática não encontram consenso na comunidade de pesquisadores em Etnomatemática. Isso fica claro no artigo publicado por Pedro Paulo Scandiuzzi (SCANDIUZZI, 2002), que usa a metáfora água e óleo para se referir às incompatibilidades teóricas entre Modelagem e Etnomatemática. Para Scandiuzzi, a Modelagem procura validar os modelos matemáticos produzidos por grupos culturais, a partir dos critérios da matemática acadêmica, enquanto que a Etnomatemática busca compreender esses modelos na forma em que se apresentam nas culturas que os produz.

De acordo com a Etnomodelagem, proposta por Rosa e Orey $(2003 ; 2005 ; 2012 ; 2013)$, o que distingue as abordagens realizadas por meio da Modelagem daquelas feitas a partir da Etnomatemática, é que a primeira promove uma visão ética (de fora da cultura) e a outra uma visão êmica (de dentro da cultura) dos modelos produzidos por diferentes grupos, os etnomodelos. Nesses termos, "a abordagem ética corresponde à visão do eu em direção ao outro, ao passo que a abordagem êmica corresponde a uma visão do eu em direção ao nosso" (ROSA; OREY, 2012, p. 867).

A Etnomodelagem busca, justamente, superar a dicotomia entre as abordagens êmica e ética oferecendo como alternativa a abordagem dialética, com base no diálogo entre essas duas. Nessa abordagem, os etnomodelos são considerados tanto em termos dos valores próprios à cultura em que são produzidos (abordagem êmica), como dos valores relativos à matemática acadêmica (abordagem ética).

Nesse sentido, Rosa e Orey (2012) sugerem a Etnomodelagem, com base na abordagem dialética, como uma possibilidade para a construção de um currículo matemático escolar integrado ao conhecimento matemático de grupos culturais distintos. Assim, de acordo com os autores,

Um currículo baseado na perspectiva da etnomodelagem providencia uma base ideológica para a aprendizagem que utiliza os diversos elementos culturais e linguísticos dos membros de grupos culturais distintos na ação pedagógica para o ensino de matemática. (ROSA; OREY, 2010a apud ROSA; OREY, 2012, p. 876).

Rosa e Orey (2013) relatam uma experiência na qual a Etnomodelagem é utilizada como prática educativa em contexto não escolar. Trata-se de uma atividade desenvolvida por Daniel Orey com estudantes universitários e alunos da rede municipal de ensino da cidade de Ouro Preto (MG). Nessa atividade, os alunos fazem uso da Etnomodelagem para modelar uma 
curva, que é parte do detalhe arquitetônico do muro do prédio de um antigo colégio da referida cidade, o Colégio Arquidiocesano de Ouro Preto. Essa experiência educacional mostra o potencial da Etnomodelagem como abordagem pedagógica para o currículo de Educação Matemática em todos os níveis educacionais. Porém, nenhuma tese e/ou dissertação desenvolvida no âmbito da UFOP, na qual os pesquisadores em questão estão lotados, veio a contemplar essa abordagem.

Não há no banco de teses e dissertações da UFOP, Universidade em que os referidos pesquisadores estão lotados, nem em seus respectivos Currículos Lattes. Nenhuma dissertação ou tese sob a orientação desses autores, em que a etnomodelagem é abordada ainda em pesquisa.

Nesse sentido, pesquisas com base nesse aporte teórico configuram possibilidades em aberto no Programa de Mestrado Profissional daquela instituição. Vale ressaltar, porém, que o caráter regional das possibilidades investigativas sobre a etnomodelagem se sustenta no fato dos pesquisadores Milton Rosa e Daniel Clark Orey, ambos de atuação e reconhecimento internacional, serem professores/pesquisadores do Programa de Mestrado Profissional em Educação Matemática da UFOP; no âmbito do qual orientam dissertações de mestrado.

\section{Considerações finais}

A presente investigação realizada situa-nos nas pesquisas realizadas em solo mineiro em Modelagem Matemática no âmbito da Educação Matemática para conhecimento da comunidade de pesquisadores da área, das escolhas epistemológicas e metodológicas efetuadas em suas investigações.

Em termos estritamente quantitativos, os números revelam que a produção de pesquisas dentro da linha Modelagem em Minas Gerais é ainda incipiente. Por outro lado, se levarmos em conta o fato de que a primeira dissertação de mestrado foi defendida em 2011, há apenas quatro anos, podemos considerar que tal produção, apesar de ainda escassa, pode ser considerada promissora. Podemos vislumbrar esse futuro promissor da Modelagem mineira levando em conta alguns fatores.

No Programa de Mestrado Profissional em Educação Matemática da UFOP, por exemplo, seis dos seus treze professores/pesquisadores têm a Modelagem como um de seus temas de 
interesse. Nessa mesma universidade está em atividade um grupo de pesquisa sobre Modelagem na Educação Matemática.

No programa de pós-graduação em Educação da UFMG, temos a relevante produção da professora/pesquisadora Jussara de Loiola Araújo que coordenada naquela instituição um grupo de pesquisa sobre Modelagem na Educação Matemática.

Já no Programa de Mestrado Profissional em Educação Matemática da UFJF, ainda não há uma linha de pesquisa sobre Modelagem estabelecida. Porém, a Modelagem se faz presente, na disciplina Metodologias Alternativas de Ensino da Matemática, regularmente, ofertada naquele programa.

Outro indicativo de um futuro promissor das pesquisas em Modelagem, em terras mineiras, são as dissertações de mestrado e as teses de doutorado que estão em andamento. Na UFOP temos duas dissertações em curso, uma sendo desenvolvida por Laércio Conceição Pedrosa Nogueira, sob a orientação de Frederico da Silva Reis e outra por Denilson Gomes Campos, orientada por Regina Franchi.

Na UFMG estão em andamento a dissertação de Ana Paula Francisca Pires da Rocha e a tese de doutorado de Célio Roberto Melillo, ambas orientadas por Jussara Araújo. Na UFJF, temos a dissertação de mestrado de Neil da Rocha Canedo Jr sendo orientada por Marco Aurélio Kistemann Jr.

A respeito da revisão de literatura nas dissertações e teses defendidas em Minas Gerais, percebemos que os objetivos das pesquisas são bastante diversos. Vão desde um levantamento das perspectivas de Modelagem no cenário nacional (BUENO, 2011) até a análise da possibilidade da Modelagem como ferramenta didática para o desenvolvimento de um conteúdo específico (ABREU, L. 2011), passando por questões relativas à formação de professores em práticas de Modelagem (ABREU, G. 2011; SILVA, 2012), relações entre o contexto sócio-histórico do aluno e sua participação em ambientes de Modelagem (CAMPOS, 2013), questões de ordem epistemológica, relativas ao processo de matematização (FREITAS, 2013) e as relações entre a Modelagem e a educação progressiva de John Dewey com elementos de Educação Estatística (MELLILO, 2011).

Sobre os aportes teóricos utilizados nessas pesquisas, há certa predominância de referências aos pressupostos e categorias da Educação Matemática Crítica. Dessa forma, a Modelagem 
em Minas Gerais reflete uma tendência observada por Malheiros (2012, p. 870) no cenário nacional. "Quando analisamos a produção científica acerca da Modelagem em território nacional, é notória a presença, em quase sua totalidade, de referências à Educação Matemática Crítica [...]”. Contudo, foi possível observar a presença de relações entre a Modelagem e as ideias de Dewey sobre educação progressiva.

Em um levantamento que revela o contexto nacional da pesquisa em Modelagem, Malheiros (2012) destaca a presença das ideias de Dewey relativas à noção de interesse em pesquisas no âmbito da Modelagem. Contudo, as relações da Modelagem com a educação progressiva deweyana, presentes em Mellilo (2011), assim como em Mellilo e Bean (2011), parecem ser uma particularidade da pesquisa mineira em Modelagem.

Em contrapartida, Malheiros (2012) conclui que boa parte das pesquisas brasileiras em Modelagem dá destaque à relação entre esse enfoque didático e a presença das Tecnologias da Comunicação e Informação (TIC) (MALHEIROS, 2012). No caso da Modelagem em Minas Gerais, essa relação entre as TIC e a Modelagem é tratada apenas em Freitas (2013), ainda assim de forma periférica, sem uma relação direta com o tema central da investigação.

No que tange à metodologia empregada nas pesquisas, o paradigma qualitativo está sempre presente nas pesquisas mineiras em Modelagem. Percebe-se também que os autores procuram fazer ressonância entre seus objetivos investigativos, os aportes teóricos que adotam e a metodologia que empregam.

Os artigos e capítulos de livros produzidos por pesquisadores e estudantes, que atuam em Minas Gerais e que têm a Modelagem como tema, refletem a já referida presença dos aportes teóricos da Educação Matemática Crítica na pesquisa mineira em Modelagem. Isso fica evidente em Araújo (2009), Araújo, et al (2011), Araújo (2012) e Mellilo e Bean (2011).

Os artigos Rosa e Orey (2003, 2005, 2012 e 2013) apresentam ensaios teóricos nos quais vislumbramos uma senda promissora de pesquisa, tratando-se das relações entre a Modelagem e a Etnomatemática estabelecidas pelos autores na noção de Etnomodelagem.

Por fim, essa nossa investigação não pretendeu esgotar a análise da produção científica mineira sobre a temática Modelagem. Ao contrário disso, o que ela de fato revela é uma senda de pesquisa que começa a dar seus primeiros frutos e configura-se numa região de inquérito rica em possibilidades investigativas. 
Entendemos ser de grande relevância apresentar essas possibilidades para a comunidade de pesquisadores em Educação Matemática, principalmente aqueles que pretendem assumir a Modelagem como lócus investigativo. Fica o convite para futuras pesquisas nessa área.

\section{Referências}

ABREU, Glaucos Ottone Cardoso. A prática de Modelagem Matemática como um cenário de investigação na formação continuada de Professores de Matemática. Dissertação (Mestrado em Educação Matemática) - Instituto de Ciências Exatas e Biológicas, Universidade Federal de Ouro Preto, Ouro Preto, 2011.

ABREU, Lorena Luquini Barros. Estudando conteúdos matemáticos com direcionamentos de Modelagem Matemática: o caso da função afim. Dissertação (Mestrado em Educação Matemática) - Instituto de Ciências Exatas, Universidade Federal de Juiz de Fora, Juiz de Fora, 2011.

ARAÚJO, Jussara de Loiola; FREITAS, Wanderley Sebastião; SILVA, Alessandra Cristina. Construção de modelos matemáticos: uma experiência na divisão de recursos financeiros. In: ALMEIDA, L Lourdes Maria Werle de; ARAÚJO, Jussara de Loiola.; BISOGNIN, E. (org) Práticas de Modelagem Matemática: relatos de experiências e propostas pedagógicas. Londrina: Eduel, 2011.

ARAÚJO, Jussara de Loiola; FREITAS, Wanderley Sebastião; SILVA, Alessandra Cristina. Pesquisas sobre Modelagem em Eventos Científicos Recentes de Educação Matemática no Brasil. In: SEMINÁRIO INTERNACIONAL DE PESQUISA EM EDUCAÇÃO MATEMÁTICA, 4., 2009, Brasília, DF. Anais... Brasília: Universidade Católica de Brasília. p. 1-19, 2009. 1 CD-ROM.

ARAÚJO, Jussara de Loiola. Ser Crítico em Projetos de Modelagem em uma Perspectiva Crítica de Educação Matemática. Bolema, Rio Claro (SP), v. 26, n. 43, p. 839-859, ago. 2012.

ARAÚJO, Jussara de Loiola. Uma Abordagem Sócio-Crítica da Modelagem Matemática: a perspectiva da educação matemática crítica. In: Alexandria - Revista de Educação em Ciência e Tecnologia, Florianópolis, v. 2, n. 2, p. 69-85, jul. 2009. Disponível em: $<$ http://alexandria.ppgect.ufsc.br/publicacoes-2009/v2-n2-072009/>. Acesso em: 30 mar. 2014.

BARBOSA, Jonei Cerqueira; CALDEIRA, Ademir. Donizeti; ARAÚJO, Jussara de Loiola. Modelagem Matemática na Educação Matemática Brasileira: Pesquisas e Práticas Educacionais. Recife: Sbem, p. 195-211. (Biblioteca do Educador Matemático). V.3, 2007.

BARBOSA, Jonei Cerqueira. Modelagem Matemática: Concepções e Experiências de Futuros Professores. 2001. 268f. Tese (Doutorado em Educação Matemática) - Instituto de Geociências e Ciências Exatas, Universidade Estadual Paulista, Rio Claro, 2001. 
BARBOSA, Jonei Cerqueira. Sobre a pesquisa em modelagem matemática no Brasil. In: Conferência Nacional sobre Modelagem na Educação Matemática, 5, Ouro Preto. Anais... UFOP/UFMG, 2007. p. 82-103, 2007. 1 CD-ROM.

BOGDAN, Robert; BIKLEN, Sari. Investigação qualitativa em Educação: fundamentos, métodos e técnicas. In: Investigação qualitativa em educação. Portugal: Porto Editora, p. 1580, 1994.

BORBA, Marcelo de Carvalho; SKOVSMOSE, Ole. The Ideology of Certainty in Mathematics Education. In: For the Learning of mathematics: an international journal of mathematics education, vol. 17, n.3, p.17-24, 1997.

BUENO, Vilma Candida. Concepções de Modelagem Matemática e subsídios para a educação matemática: quatro maneiras de compreendê-la no cenário brasileiro. Dissertação (Mestrado em Educação Matemática) - Instituto de Ciências Exatas e Biológicas, Universidade Federal de Ouro Preto, Ouro Preto, 2011.

BURAK, Dionísio. As Diretrizes Curriculares para o Ensino de Matemática e a Modelagem Matemática. Perspectiva, Erechim, v. 29, n. 113, p. 153-161, 2005.

BURAK, Dionísio. Modelagem Matemática e a Sala de Aula. In: I EPMEM -Encontro Paranaense da Modelagem Na Educação Matemática, 2004, Londrina. Anais... Londrina: I EPMEM, 2004.

BURAK, Dionísio. Modelagem Matemática: avanços, problemas e desafios. In: Encontro Paranaense de Modelagem em Educação Matemática, II, Apucarana Anais... Apucarana: FAP, 2006.

CACHAPUZ, António. Do sentido atual da pesquisa em formação de professores de ciências. In: Encontro de Pesquisa em Educação em Ciências, IV, Bauru, 2003. Atas... CD-ROM.

CAMPOS, Ilaine da Silva. Alunos em ambientes de Modelagem Matemática: caracterização do envolvimento a partir da relação com o background e o foreground. Dissertação (Mestrado em Educação) - Faculdade de Educação da Universidade Federal de Minas Gerais, Belo Horizonte, 2013.

DAMIN, Maria Aparecida da Silva. Olhares nômades sobre o aprendizado na arte da Modelagem Matemática no "Projeto Ciência na Escola". Dissertação (Mestrado em Educação) - Faculdade de Educação, Universidade Estadual de Campinas, Campinas, 232f, 2004.

DEWEY, John. Como Pensamos. Tradução de Haydée de Camargo Campos. São Paulo: Companhia Editora Nacional, 1959.

FERREIRA, N. As Pesquisas denominadas "Estado da Arte". Educação \& Sociedade, ano XXIII, no 79, p. 257-272. ago/2002. 
FIORENTINI, Dario; NACARATO, Adair Mendes. Cultura, formação e desenvolvimento profissional de professores que ensinam. São Paulo: Musa Editora, GEPFPMPRAPEMFE/UNICAMP, 2005.

FREITAS, Wanderley Sebastião. A matematização crítica em projetos de Modelagem. Tese (Doutorado em Educação) - Faculdade de Educação da Universidade Federal de Minas Gerais, Belo Horizonte, 2013.

GNEDENKO, Boris Vladimirovich. A teoria da probabilidade. Tradução de Roberto Malheiros Moreira. Rio de Janeiro: Editora Ciência Moderno Ltda, 2008.

KLÜBER, Tiago Emanuel. Uma metacompreensão da Modelagem Matemática na Educação Matemática. Tese (Doutorado em Educação Científica e Tecnológica) - Centro de Ciências Físicas e Matemática, Universidade Federal de Santa Catarina, Florianópolis, 2012.

MACHADO, Elisa Spode. Modelagem Matemática e Resolução de Problemas. Dissertação (Mestrado em Educação em Ciências e Matemática). - Pontifícia Universidade Católica do Rio Grande do Sul, Porto Alegre, 141f, 2006.

MALHEIROS, Ana Paula dos Santos. Pesquisas em Modelagem Matemática e diferentes tendências em Educação e em Educação Matemática. Bolema, Rio Claro (SP), v. 26, n. 43, p. 861-882, 2012.

MELLILO, Célio; BEAN, Dale. Modelagem Matemática na atribuição de probabilidades em jogos do campeonato brasileiro de futebol. In: ALMEIDA, L Lourdes Maria Werle de; ARAÚJO, Jussara de Loiola; BISOGNIN, E. (org) Práticas de Modelagem Matemática: relatos de experiências e propostas pedagógicas. Londrina: Eduel, 2011.

MELILLO, Célio Roberto. Modelagem Matemática no futebol: uma atividade de crítica e criação encaminhada pelo método do caso. Dissertação (Mestrado em Educação Matemática) - Instituto de Ciências Exatas e Biológicas, Universidade Federal de Ouro Preto, Ouro Preto, 2011.

ROMANOWSKI, Joana Paulin; ENS, Romilda Teodora. As pesquisas denominadas do tipo "Estado da Arte" em educação. In: Revista Diálogo Educacional. Curitiba, v.6, n. 19, 2006.

ROSA, Milton; OREY, Daniel Clark. O campo de pesquisa em etnomodelagem: as abordagens êmica, ética e dialética. Educação Pesquisa, São Paulo, v. 38, n. 04, p. 865 879, out/dez, 2012.

ROSA, Milton; OREY, Daniel Clark. Tendências atuais da etnomatemática como um programa: rumo à ação pedagógica. ZETETIKÉ, Unicamp, Campinas, v. 13, n. 23, jan/jun, 2005 .

ROSA, Milton; OREY, Daniel Clark. The Mathematics of the Curves on the Wall of the Colégio Arquidiocesano and its Mathematical Models: a Case for Ethnomodeling. Journal of Mathematical Modelling and Application, v. 1, n. 8, p. 42 - 62, 2013. 
ROSA, Milton; OREY, Daniel Clark. Vinho e Queijo: Etnomatemática e Modelagem. Bolema, Rio Claro, v. 16, n. 20, p.1-16, 2003.

SCANDIUZZI, Pedro Paulo. Água e Óleo: Modelagem e Etnomatemática? Bolema, Rio Claro, v. 15, n. 17, p. 52 - 58, 2002.

SILVA, Alessandra Cristina. Possibilidades e limites vivenciados por uma professora em sua primeira experiência com Modelagem na Educação Matemática. Dissertação (Mestrado em Educação) - Faculdade de Educação da Universidade Federal de Minas Gerais, Belo Horizonte, 2012.

SKOVSMOSE, Ole. Educação Matemática Crítica: a questão da democracia. Campinas: Papirus, 2001.

SKOVSMOSE, Ole, et. al. "Antes de dividir temos que somar": 'entre-vistando' foregrounds de estudantes indígenas. Bolema - Boletim de Educação Matemática, Rio Claro, n. 34, p. 237 $262,2009$.

TAMBARUSSI, Carla Melli; KLÜBER, Tiago Emanuel. Focos da pesquisa stricto sensu em Modelagem Matemática na Educação Matemática brasileira: considerações e reflexões. Educação Matemática Pesquisa, São Paulo, v.16, n.1, p. 209-225, 2014. 